\title{
Application of a Novel 'Make and Test in Parallel' Strategy to Investigate the Effect of Formulation on the Pharmacokinetics of GDC-08 I0 in Healthy Subjects
}

\author{
Sravanthi Cheeti ' (D) Hao Helen Hou' • Eric Nelson' • Helen Walker ${ }^{2}$ • Buyun Chen ' Roland Morley' • Mary Gates ' \\ Luna Musib' • Sandhya Girish' • Srikumar Sahasranaman' • Lichuan Liu'
}

Received: 26 June 2018 / Accepted: 2 October 2018 / Published online: 15 October 2018

(C) The Author(s) 2018, corrected publication October/2018

\begin{abstract}
Purpose GDC-0810, administered orally, was used in Phase I and II clinical studies to treat estrogen receptor positive breast cancers. It contains $\mathrm{N}$-methyl-D-glucamine (NMG) salt of GDC-0810 with 10\% sodium lauryl sulfate (SLS) as a surfactant and $15 \%$ sodium bicarbonate $\left(\mathrm{NaHCO}_{3}\right)$ as an alkalizing agent to aid dissolution. To improve the processability of the formulation and reduce potential mucosal irritation in future Phase III clinical studies, the salt form and the amount of excipient required further optimization. To achieve this, we employed a novel "Make and Test in Parallel" strategy that facilitated selecting formulation in a rapid timeframe.
\end{abstract}

Methods RapidFACT ${ }^{\circledR}$, a streamlined, data-driven drug product optimization platform was used to bridge Phase I/II and Phase III formulations of GDC-0810. Five prototype formulations, varying in either the form of active pharmaceutical ingredient and/or the levels of the excipients SLS and $\mathrm{NaHCO}_{3}$ were assessed. Uniquely, the specific compositions of formulations manufactured and dosed were selected in realtime from emerging clinical data.

Results The study successfully identified a Phase III formulation with a reduced SLS content, which when administered following a low-fat meal, gave comparable pharmacokinetic exposure to the Phase I/II formulation administered under the same conditions.

The original version of this article was revised: The Publisher regrets the typesetting mistake of retaining incorrect text in the Figure I caption. The correct text for the caption is "Molecular Structure of GDC-08 I 0 NMG Salt".

Sravanthi Cheeti

cheeti.sravanthi@gene.com

Genentech, Inc., I DNA Way, MS\# 463A, Genentech, South San Francisco, California 94080, USA

2 Quotient Sciences, Mere Way, Ruddington, Nottingham, UK
Conclusions Our novel 'Make and Test in Parallel' approach enabled optimization of GDC-0810 formulation in a timeand cost-efficient fashion.

KEY WORDS food effect · formulation optimization . GDC-08 10 · pharmacokinetics · relative bioavailability

\section{ABBREVIATIONS}

$A E$

ANOVA

API

$\mathrm{AUC}_{0 \text {-inf }}$

$\mathrm{AUC}_{0-\mathrm{t}}$

$\mathrm{Cl}$

$\mathrm{C}_{\max }$

CMC

CTCAE

CV

DOE

ECG

ER

$\mathrm{ER}^{+}$

GCP

GMP

GMR

HER

ICH E6

LLOQ

$\mathrm{NaHCO}_{3}$

NMG

PK

RapidFACT ${ }^{\circledR}$

SAE
Adverse event

Analysis of variance

Active Pharmaceutical Ingredient

Area under the curve (zero to infinity)

Area under the curve (from time to last

measurable reading)

Confidence intervals

Maximum drug concentration in plasma

Chemistry, Manufacturing, and Controls

Common terminology criteria for adverse events

Coefficient of variance

Design of experiments

Electrocardiogram

Estrogen Receptor

Estrogen Receptor positive

Good Clinical Practices

General Manufacturing procedures

Geometric mean ratio

Human epidermal growth factor negative

International Conference on Harmonisation

of Technical Requirements for

Pharmaceuticals for Human Use

Lowe limit of quantification

Sodium Bicarbonate

N-Methyl-D-glucamine

Pharmacokinetics

Rapid Formulation development and

Clinical Testing

Severe adverse event 
SLS

TEAE

TPP

Sodium Lauryl Sulfate

Treatment emergent adverse effects

Target product profile

\section{INTRODUCTION}

Breast cancer is the most common form of cancer and the leading cause of cancer death in women worldwide, accounting for more than 1,670,000 new cases and nearly 522,000 cancer deaths annually (1). Approximately $70 \%$ of all breast cancers express and are dependent on the estrogen receptor $(\mathrm{ER})$ for tumor growth and progression (2). Modulation of estrogen activity and/or synthesis is the mainstay of therapeutic approach in postmenopausal women with ER-positive $\left(\mathrm{ER}^{+}\right)$breast cancer. Despite the effectiveness of available hormonal therapies such as tamoxifen, aromatase inhibitors, and ER antagonists/degraders (3), many patients relapse or develop resistance to these agents and therefore require further treatment for optimal disease control, thus representing a population with an unmet medical need. As such, there is a need for new ER-targeting therapies with increased anti-tumor activity to further delay disease progression and/or overcome resistance to the currently available hormonal therapies and ultimately prolong survival in women with $\mathrm{ER}^{+}$advanced breast cancer.

GDC-0810 was developed as an oral drug for use as a single agent, or in combination, for treatment of estrogen receptor positive $\left(\mathrm{ER}^{+}\right)$, human epidermal growth factor receptor 2 negative (HER $2^{-}$) breast cancer (4). The molecule, GDC-0810, was however a weak acid with low intrinsic solubility $(<0.06 \mu \mathrm{g} / \mathrm{ml})$, an acidic $\mathrm{pK}_{\mathrm{a}}$ of 4.3 and a $\log P$ value of 6.2. GDC-0810 NMethyl-D-glucamine (NMG) salt was selected as the solid form for clinical development as an immediate release tablet formulation using a dose strength of $200 \mathrm{mg}$ (free acid equivalent) for use in Phase I and II clinical studies at a single daily dose of $600 \mathrm{mg}$. In general, the salt form of a weakly ionizable acid or base is expected to have a higher dissolution rate than the free form. However, due to super-saturation, the salt may sometimes precipitate out as the insoluble free form upon dissolution, forming a layer on the surface of the dissolving salt, which may result in low bioavailability of the drug. The addition of functional excipients, such as surfactants and $\mathrm{pH}$ modifiers, in the dosage forms have been reported to be an effective tool in improving the dissolution behavior of compounds with $\mathrm{pH}$ dependent solubility $(5,6)$. Further, in vitro dissolution studies have shown that incorporating 15\% sodium bicarbonate $\left(\mathrm{NaHCO}_{3}\right)$ as an alkalizing agent in the solid dosage form of GDC-0810 can enhance its release via micro-environmental $\mathrm{pH}$ modulation, resulting in increased dissolution (7).

In addition to $15 \% \mathrm{NaHCO}_{3}$, the Phase I/II formulation also contained $10 \%$ sodium lauryl sulfate (SLS) as a surfactant. As the percentage of SLS, a mucosal irritant, used in this formulation was rather high, some gastro-intestinal toxicities were expected (8). Additionally, the high level of SLS resulted in poor processability of the formulation and caused significant challenges during tablet manufacturing. Moreover, GDC-0810 N-Methyl-D-glucamine (NMG - 195 g/mol) salt also added substantial counter ion weight to the formulation, thus decreasing the formulation space for a high drug-loading tablet. In summary, the amount of excipient in the formulation that was being used in the Phase I/II studies appeared to be suboptimal given early clinical data indicating a potential risk of diarrhea with GDC-0810. Therefore, further optimization of this formulation was required for clinical studies.

The 'conventional' process for development of formulations relies on pre-clinical models to screen prototype formulations and select candidates for clinical evaluation. These candidates are then scaled up and characterized to provide a package of CMC data supporting a product shelf life of at least three months, prior to proceeding to a human clinical study to establish whether the target product profile (TPP) has been met. The only formulation(s) available for dosing in the relative bioavailability study are therefore manufactured weeks or months in advance. However, the poor predictive power of pre-clinical models as previously reported (9) is a limitation and the TPP is frequently not achieved in the first iteration, which often requires multiple cycles of in vitro, pre-clinical, product manufacturing and clinical dosing to optimize the formulation, significantly increasing the time and cost of development.

To address this limitation, we employed a novel 'Make and Test in Parallel' strategy for rapid development and optimization using Rapid Formulation development and Clinical Testing (RapidFACT $®)$. RapidFACT $®$ is a streamlined, data-driven approach for formulation optimization under which drug products can be manufactured within 7 days of dosing at a small scale, removing scale-up and stability package generation from the critical path to obtaining clinical data on product performance. In addition, the integrated GMP manufacturing and clinical research facility allows clinical data from one study period to be reviewed and used to select the product to be manufactured and evaluated on the next dosing occasion, with typically only 14 days between dosing occasions. This therefore allows a series of formulations to be iteratively 'made and tested' as part of a crossover study design within a single group of volunteers. This approach has been successfully applied to optimize the dose and bioavailability of drugs in over 200 formulations (10-14). This strategy uses real-time adaptive manufacturing to support an adaptive study design. Decision-making data are generated using the proposed study design to inform formulation selection in a rapid timeframe. This provides flexibility in adjusting formulation composition based on the rapid generation and analysis of interim clinical data results in reduced consumption of Active Pharmaceutical Ingredient (API), accelerated timelines, and overall cost-effective decision-making. RapidFACT $\AA$ flexibility can be maximized through the definition of a 'formulation design space', bracketing levels of critical-to-performance 
components in the formulation from which compositions can be selected during clinical conduct. By generating representative technical data prior to the study at the 'corner point' compositions of the design space, assurance of product quality of any specific compositions described therein is provided (11).

A relative bioavailability study, using the above-mentioned approach, was conducted to identify a prototype formulation with the optimal form of the active pharmaceutical ingredient as well as the optimal concentration of SLS and/or $\mathrm{NaHCO}_{3}$, which would provide comparable pharmacokinetics to the Phase I/II formulation. By using the 'Make and Test in Parallel' approach, a total of five prototype formulations of GDC-0810, varying in either the form of active pharmaceutical ingredient and/or the levels of the excipients SLS and $\mathrm{NaHCO}_{3}(2-10 \%$ and 5-15\%, respectively), were studied. In addition, the effect of food on the bioavailability of the selected formulation was investigated.

\section{MATERIALS AND METHODS}

This study was conducted at Quotient Sciences (Nottingham, $\mathrm{UK}$ ), in full conformance with the ICH E6 guideline for GCP and the principles of the Declaration of Helsinki, or the laws and regulations of the country in which the research is conducted, whichever afforded the greater protection to the individual. The study complied with the requirements of the ICH E2A guideline (Clinical Safety Data Management: Definitions and Standards for Expedited Reporting) and the E.U. Clinical Trial Directive (2001/20/EC). All subjects provided written informed consent.

The study was conducted as a RapidFACT $®$ program which uses real-time adaptive manufacturing and screening of new formulations in humans using Quotient's integrated GMP manufacturing and clinical research facility. Using this platform, drug products were selected within a continuous formulation design space where a range of product performance attributes was obtained by varying the quantitative composition of SLS and $\mathrm{NaHCO}_{3}$ in the formulation.

\section{Tablets}

Reference GDC-0810 Phase II NMG salt tablets were supplied by Genentech Inc. as $200 \mathrm{mg}$ tablets for oral administration packaged as per the product label. The molecular structure of GDC-0810 NMG salt is shown in Fig. 1. The GDC-0810 drug substance and drug product intermediate for the manufacture of the Phase III prototype tablets were also provided by Genentech Inc. GDC-0810 Phase III prototype tablets were manufactured and supplied in real-time by Quotient Sciences as $200 \mathrm{mg}$ tablets for oral administration. The composition of Phase II and III GDC-0810 tablets administered in the relative bioavailability study are summarized in Table I

\section{Clinical Study Design}

This relative bioavailability study was a Phase I, single center, open-label, randomized, 3-part crossover study in separate cohorts of healthy female subjects of non-childbearing potential. Each study part consisted of a screening period of up to 28 days, a study period of 4 days (Day -1 to Day 3; 4 periods in Part 1 and 3 periods in each of Parts 2 and 3 ) in which study drug was administered on Day 1 of each period, and a minimum follow-up period of 28 days. Study participation for each subject was approximately 10 weeks.

Blood samples for the measurement of GDC-0810 plasma concentrations were obtained through $48 \mathrm{~h}$ post dose in each period. There was a minimum washout period of 3 days between each dose administration based on the mean half-life of approximately $8 \mathrm{~h}$ in patients. Safety data, in the form of repeated measures of vital signs, electrocardiograms (ECGs), clinical examinations, clinical laboratory testing, and a record of adverse events (AEs), were recorded.

The primary objective of Part 1 of the study was to determine the relative bioavailability of GDC-0810 Phase III prototype formulations, with varying levels of the excipients, SLS and $\mathrm{NaHCO}_{3}$, with respect to the control (Phase II tablet formulation). The primary objective of Part 2 of the study was to determine the relative bioavailability of GDC-0810 Phase III prototype formulations, with varied form of active pharmaceutical ingredient i.e., Free Acid and Spray-Dried Amorphous Dispersion (and optimal levels of excipients identified in Part 1), with respect to the control (Phase II tablet formulation). Subjects in both Parts 1 and 2 received $200 \mathrm{mg}$ dose with a standardized low-fat food to mimic recommended prandial condition in the clinical studies. The primary objective of Part 3 was to assess the PK of GDC-0810 using a Phase III prototype tablet formulation selected from Parts 1 and 2 (administered with low-fat food or under fasted conditions) at the current clinical dose of $600 \mathrm{mg}$ with respect to the current Phase II tablet formulation administered with low fat food.

Healthy female volunteers of non-childbearing potential were chosen for this study to assess the PK effects of GDC0810 within a dose range that was expected to be well tolerated. No formal sample size calculation was performed. However, a minimum sample size of 12 healthy volunteers for each part of the study was considered sufficient to achieve the objectives.

\section{Parts I \& 2}

Part 1 was a four-period crossover design to investigate the effect of excipient levels on the PK of GDC-0810 administered (Fig. 2a). A total of 17 subjects were enrolled in Part 1 to complete a minimum of 12 subjects in each study period. Part 2 was a 3-period crossover design to investigate the effect of varied form of active pharmaceutical ingredient on the PK of GDC-0810 administered (Fig. 2b). A total of 15 subjects 


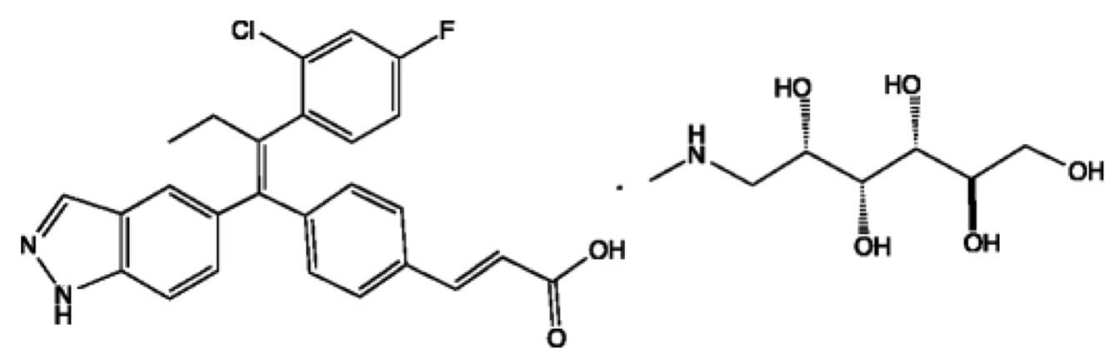

Fig. I Molecular Structure of GDC-08 I 0 NMG Salt

were enrolled in Part 2 to complete a minimum of 12 subjects in each study period.

On Day 1 of each study period, each subject received a single $200 \mathrm{mg}$ dose of GDC-0810 (as a Phase II tablet or one of five Phase III prototype tablet formulations) administered $30 \mathrm{~min}$ after the start of the low-fat meal across all periods. Subjects were randomized to one of the treatment sequences for Treatments A, B, C in Part 1 and Treatments E, F, G in Part 2, with an additional fixed treatment consisting of Treatment $\mathrm{D}$ in Part 1. An interim decision was made, based on the available safety, tolerability, and PK data following completion of Period 3 , to select the formulation to be dosed in Period 4 in Part 1. The decision to proceed with Part 2 was taken after review of the PK, safety, and tolerability data from Part 1 of the study. Following review of safety, tolerability, and PK data from Parts 1 and 2, the decision to proceed with Part 3 was taken.

\section{Part 3}

Part 3 was a 3-period crossover design to compare the PK of a Phase III prototype tablet formulation, selected from Parts 1 and 2, with the Phase II tablet formulation (both administered after ingestion of a low-fat meal) at the current clinical dose of
$600 \mathrm{mg}$, and to investigate the PK of the selected Phase III prototype formulation in the fasted state (Fig. 2c). A total of 15 subjects were enrolled in Part 3 to complete a minimum of 12 subjects in each study period.

On Day 1 of each study period, each subject received a single dose of $600 \mathrm{mg}$ GDC-0810 administered as $3 \times 200 \mathrm{mg}$ across 3 periods; a) as a Phase II tablet administered $30 \mathrm{~min}$ after the start of a low-fat meal, b) as a Phase III prototype tablet formulation administered in the fasted state, and c) as a Phase III prototype tablet formulation administered $30 \mathrm{~min}$ after the start of a low-fat meal. The composition of Phase II tablet and Phase III prototype tablet used in Part 3 was based on the review of available data from Parts 1 and 2. Subjects were randomized to one of three treatment sequences.

\section{Dose Rationale}

The recommended clinical dose of GDC-0810 was $600 \mathrm{mg}$, administered orally as three $200 \mathrm{mg}$ tablets. It was demonstrated in a clinical Phase I/IIa study that increasing the dose of GDC-0810 over the range of $100 \mathrm{mg}$ to $800 \mathrm{mg}$ resulted in a dose proportional increase in plasma exposure. Based upon the clinical experience with GDC-0810 to date, GDC-0810
Table I Composition of Phase II and III GDC-08I0 Tablets Administered in Parts 1, 2, and 3 of the Relative Bioavailability Study

\begin{tabular}{|c|c|c|c|c|}
\hline \multirow[t]{2}{*}{ IMP } & \multicolumn{3}{|l|}{ Composition } & \multirow[t]{2}{*}{ Treatment } \\
\hline & API form & SLS & $\mathrm{NaHCO}_{3}$ & \\
\hline Phase II Tablet & NMG salt & $10 \%$ & $15 \%$ & $\mathrm{~A}^{\mathrm{a}}, \mathrm{E}^{\mathrm{a}}$ and $\mathrm{H}^{\mathrm{a}}$ \\
\hline \multicolumn{5}{|c|}{ Phase III Prototype Tablet Formulations } \\
\hline Prototype I & NMG salt & $2 \%$ & $15 \%$ & $\mathrm{~B}^{\mathrm{a}}$ \\
\hline Prototype 2 & NMG salt & $2 \%$ & $10 \%$ & $C^{a}$ \\
\hline Prototype 3 & NMG salt & $2 \%$ & $5 \%$ & $D^{a}$ \\
\hline Prototype 4 & Free acid & $2 \%$ & $15 \%$ & $F^{a}$ \\
\hline Prototype 5 & Spray-dried amorphous solid dispersion & $2 \%$ & $15 \%$ & $\mathrm{G}^{\mathrm{a}}$ \\
\hline Prototype I & NMG salt & $2 \%$ & $15 \%$ & $\mathrm{I}^{\mathrm{b}}$ \\
\hline Prototype I & NMG salt & $2 \%$ & $15 \%$ & $\mathrm{j}^{\mathrm{a}}$ \\
\hline
\end{tabular}

IMP, investigational medicinal product; $\mathrm{API}$, active pharmaceutical ingredient; $\mathrm{NMG}, \mathrm{N}$-methyl glucamine; $\mathrm{NaHCO}_{3}$, sodium bicarbonate; SLS, sodium lauryl sulfate

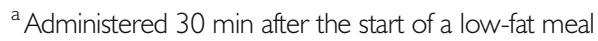

${ }^{\mathrm{b}}$ Administered in the fasted state (minimum 8-h fast) 
Fig. 2 Study Schematic for Parts I, 2, and 3 of the

Relative Bioavailability Study.

Panel (a): Treatment A: 200 mg

Phase II tablet; NMG salt; I0\% SLS

and $15 \% \mathrm{NaHCO}$. Treatment $\mathrm{B}$ :

200 mg Phase III Prototype I tablet;

NMG salt; $2 \%$ SLS and I5\%

$\mathrm{NaHCO} 3$. Treatment C: $200 \mathrm{mg}$

Phase III Prototype 2 tablet; NMG

salt; $2 \%$ SLS and $10 \% \mathrm{NaHCO} 3$.

Treatment D: 200 mg Phase III

Prototype 3 tablet; NMG salt; 2\%

SLS and 5\% NaHCO3 (formulation parameters were determined

following Period 3). Panel (b):

Treatment E: 200 mg Phase II tablet;

NMG salt; I0\% SLS and I5\%

NaHCO3. Treatment F: 200 mg

Phase III Prototype 4 tablet; Free acid; 2\% SLS and I5\% NaHCO3.

Treatment G: 200 mg Phase III

Prototype 5 tablet; Spray-dried

amorphous solid dispersion; 2\%

SLS and I5\% NaHCO3 Panel (c):

Treatment H: $3 \times 200$ mg Phase II

tablet (NMG salt; I0\% SLS and

I $5 \%$ NaHCO3), administered

30 min after a low-fat meal.

Treatment I: $3 \times 200 \mathrm{mg}$ Phase III

Prototype tablet selected from Parts

I \& 2 (NMG salt; 2\% SLS and I 5\%

$\mathrm{NaHCO} 3)$, administered in the

fasted state. Treatment J: $3 \times$

200 mg Phase III Prototype tablet

selected from Parts I \& 2 (NMG

salt; 2\% SLS and I5\% NaHCO3),

administered 30 min after a low-fat

meal. a

Treatment
Sequence

$\mathbf{N}$

1

6

26

3

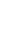

6

b Treatment

Sequence

4

5

6

Period 1

Period 2

Period 3

Period 4

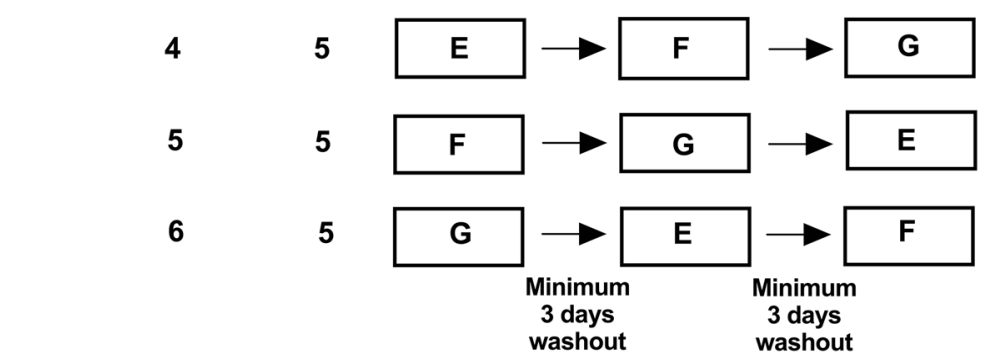

C

Treatment
Sequence
7
8

5

5
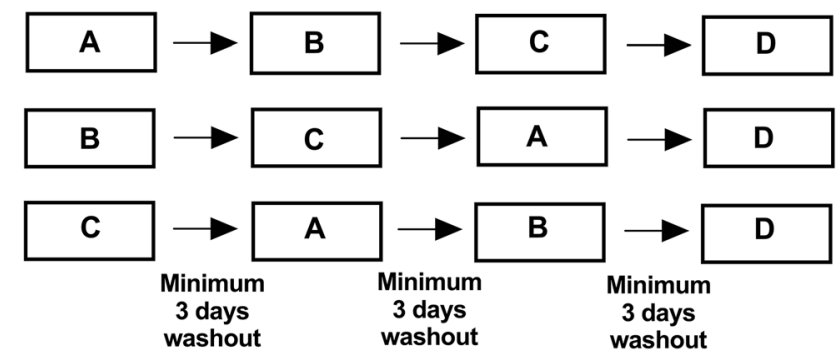

N Period $1 \quad$ Period $2 \quad$ Period 3

5

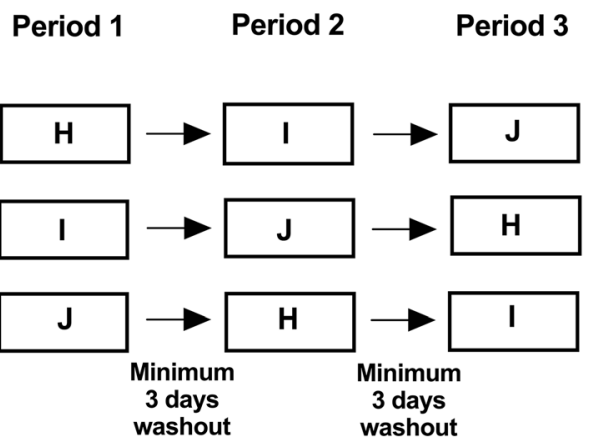

0810 at pre-dose, $0.5,1,2,3,4,6,8,12,16,24,36$, and $48 \mathrm{~h}$ post dose in each part. Plasma concentrations of GDC-0810 were determined using validated bioanalytical methods (Covance Laboratories Ltd., Harrogate, UK). The lower limit of quantification (LLOQ) was $5 \mathrm{ng} / \mathrm{ml}$.

Pharmacokinetic parameter estimates of plasma concentrations of GDC-0810 for each study part were obtained using Phoenix WinNonlin PK software (v6.3, Certara USA, Inc., St. Louis, MO, USA).

\section{Statistical Analysis}

In Parts 1 and 2, the effect of formulation on the PK of GDC-0810 was evaluated. In Part 3, the effect of food on 
the PK of the selected Phase III prototype formulation was evaluated, and a comparison of the selected Phase III prototype tablet with the Phase II tablet after ingestion of a low-fat meal was made.

Phase III prototype tablets 1, 2, or 3 were compared against Phase II tablet in Part 1 and Phase III prototype tablets 4 or 5 were compared against Phase II tablet in Part 2. All the tablets in Parts 1 \& 2 were administered after ingestion of a low-fat meal.

Phase III prototype tablet selected from Parts 1 and 2 was also compared against Phase II tablet, both administered after ingestion of a low-fat meal, in Part 3. In addition, the effect of low-fat food $v s$. fasted conditions on Phase III prototype tablet was compared in Part 3.

Formal statistical analyses for all treatments were performed on the $\mathrm{PK}$ parameters $\mathrm{C}_{\max }, \mathrm{AUC}_{0-\mathrm{t}}$, and $\mathrm{AUC}_{0 \text {-inf }}$. The PK parameters underwent natural logarithmic transformations and were subsequently analyzed using mixed effect analysis of variance (ANOVA) modeling techniques. The model included terms for treatment (i.e., GDC-0810 tablet, by formulation), period (Part 2 only) and sequence as fixed effects, and subject nested within sequence as a random effect. Adjusted geometric mean ratios (GMRs) and 90\% confidence intervals (CIs) for the adjusted GMRs for the pairwise treatment comparisons were calculated, where the ratio was defined as test/reference or fed/fasted. $P$-values for the null hypothesis that the GMR $=100 \%$ were presented. All decisions concerning the formulation selection for GDC-0134 were based on these $p$-values estimated based on relative exposures with respect to the reference.

\section{RESULTS}

\section{Demographic, Safety, and Tolerability Data}

Seventeen healthy female subjects (16 white and 1 Asian) between 50 and 69 years of age were enrolled into Part 1 of the study. Fifteen healthy female subjects (14 white and 1 Asian) between 50 and 69 years of age were enrolled into Part 2 of the study. Thirteen healthy female subjects (11 white and 2 Asian) between 46 and 68 years of age were enrolled into Part 3 of the study.

Fifteen out of the 17 enrolled subjects in Part 1 completed the study in accordance with the protocol. Oral administration of GDC-0810 at single dose levels of $200 \mathrm{mg}$ and $600 \mathrm{mg}$ was generally well tolerated under the conditions of the study. There were no serious adverse event (SAEs), severe or lifethreatening treatment emergent adverse events (TEAEs, CTCAE Grade 3 or more), or TEAEs leading to death. There were no clinically significant changes in vital signs, electrocardiographs (ECGs), or physical examination findings recorded during the study.

\section{Pharmacokinetic Results}

\section{Part I}

In Part 1, three prototype formulations of GDC-0810 as NMG salt (200 mg tablets) were studied (Treatments B, C and $\mathrm{D})$; each prototype varied in the levels of the excipients SLS and $\mathrm{NaHCO}_{3}$. Treatment A (Phase II tablet) had 10\% SLS and 15\% $\mathrm{NaHCO}_{3}$; Treatment B (Phase III prototype 1) had 2\% SLS and 15\% $\mathrm{NaHCO}_{3}$; Treatment $\mathrm{C}$ (Phase III prototype 2) had 2\% SLS and $10 \% \mathrm{NaHCO}_{3}$; and Treatment D (Phase III prototype 3) had 2\% SLS and 5\% $\mathrm{NaHCO}_{3}$.

Plasma concentration-time profiles and PK parameters of GDC-0810 following administration of Treatments A to D are shown in Fig. 3a and Table II, respectively. Geometric mean ratios (GMR) of GDC-0810 as Treatments B, C, and $\mathrm{D}$ relative to the reference formulation (Treatment $\mathrm{A}$ ) are summarized in Table II.

Treatments C and D showed statistically significantly lower levels of peak exposure, as measured by $\mathrm{C}_{\max }$ (approximately 22\% lower; $p=0.05$ and $34 \%$ lower; $p=0.002$, respectively), when compared to the reference. However, there was no significant difference in peak exposure between Treatment $B$ and reference $(p=0.12)$.

In addition, Treatments B and D showed statistically significantly lower levels of total exposure, as measured by $\mathrm{AUC}_{0-\mathrm{t}}$ when compared to Treatment $\mathrm{A}$ reference formulation $(10 \%$ lower; $p=0.085$ and $18 \%$ lower; $\mathrm{p}=0.002$, respectively). However, there was no significant difference in total exposure, when measured by $\mathrm{AUC}_{0-\mathrm{t}}$, between Treatment $\mathrm{C}$ and reference $(p=0.11)$.

\section{Part 2}

In Part 2, two further prototype formulations of GDC0810 as $200 \mathrm{mg}$ tablets were studied; each prototype varied in the form of active pharmaceutical ingredient. Treatment E (Phase II tablet) had NMG salt, 10\% SLS and $15 \% \mathrm{NaHCO}_{3}$; Treatment $\mathrm{F}$ (Phase III prototype 4) was a Free Acid, with 2\% SLS and 15\% $\mathrm{NaHCO}_{3}$; and Treatment G (Phase III prototype 5) was a SprayDried Amorphous Dispersion, with 2\% SLS and 15\% $\mathrm{NaHCO}_{3}$.

Plasma concentration-time profiles and PK parameters of GDC-0810 following administration of Treatments E to $\mathrm{G}$ are shown in Fig. 3b and Table III, respectively. GMRs of GDC-0810 as Treatments F and G relative to the reference formulation (Treatment E) are summarized in Table III.

There was no significant difference in peak exposure, as measured by $\mathrm{C}_{\max }$, between each of Treatments $\mathrm{F}$ and 
Fig. 3 Comparison of GDC08 I 0 Plasma PK. Panel (a):

Treatments A to D in Part I with 200 mg GDC-08 I0. Panel (b): Treatments $E$ to $G$ in Part 2 with 200 mg GDC-08 I0; and Panel (c): Treatments $\mathrm{H}$ to $\mathrm{J}$ in Part 3 with 600 mg GDC-08 10. Dotted line represents median; Solid line represents arithmetic mean; box represents interquartile range (IQR;

25th-75th quartiles); IQR tails default to I.5xIQR and values beyond IQR tails shown as outliers; * indicates statistically significant difference relative to the reference. a
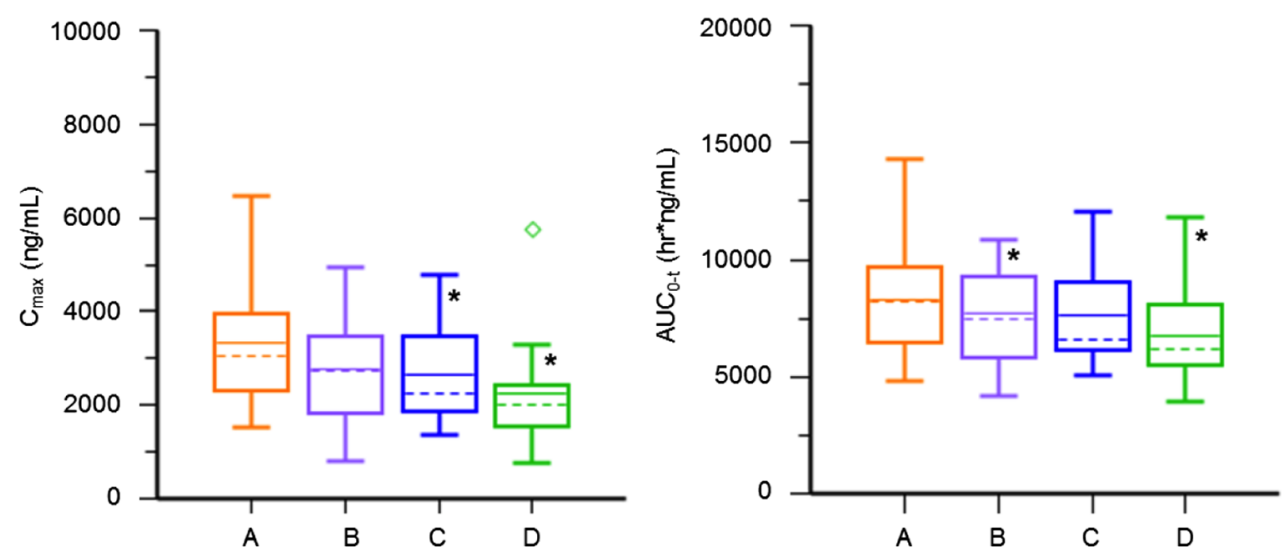

b
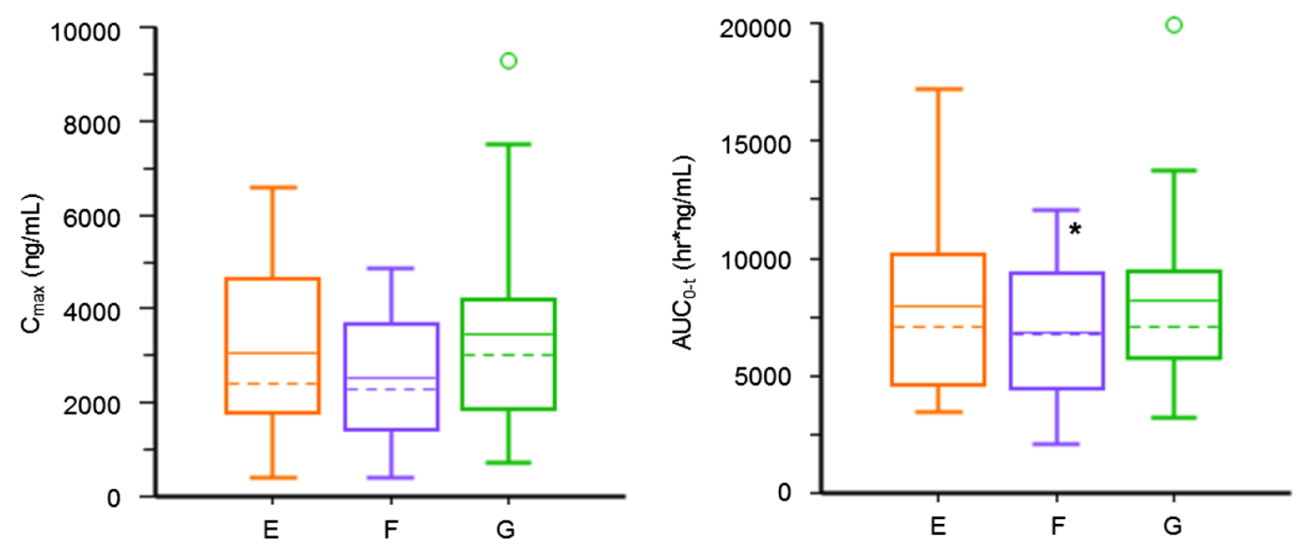

C

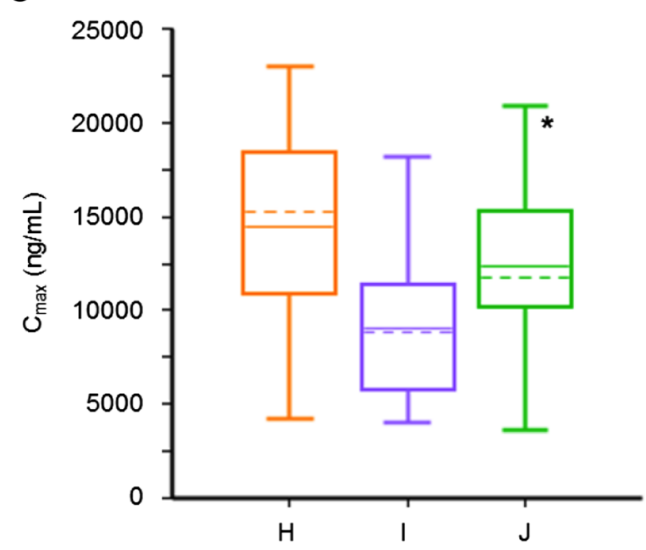

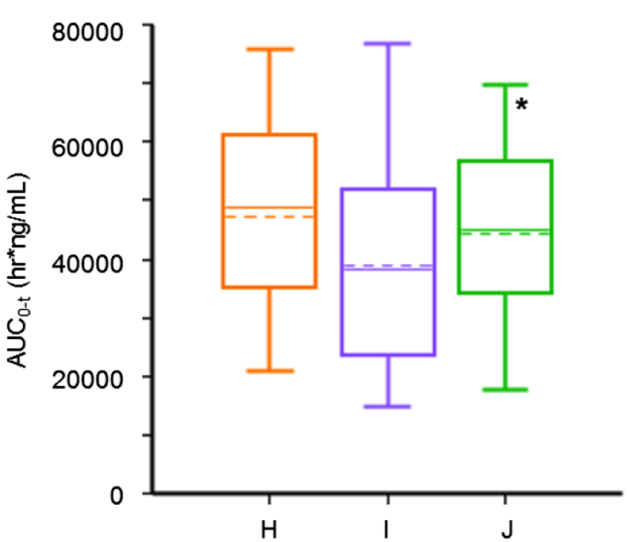

$\mathrm{G}$ when compared to the reference $(p=0.13$ and $p=0.35$, respectively). There was also no statistically significant difference in total exposure between Treatment $\mathrm{G}$ compared to reference when measured by $\mathrm{AUC}_{0-\mathrm{t}}(p=0.69)$. However, Treatment $\mathrm{F}$ showed statistically significantly lower levels of total exposure compared to Treatment $\mathrm{E}$ reference formulation when measured by $\mathrm{AUC}_{0-\mathrm{t}}(14 \%$ lower; $p=0.006$ ).
Part 3

In Part 3, the Phase III prototype formulation (selected from Part 2) of GDC-0810 as $600 \mathrm{mg}$ tablets was studied with lowfat food and under fasted conditions along with the Phase II tablet (reference) administered with low-fat food. The dose for all treatments was $600 \mathrm{mg}$. Treatment $\mathrm{H}$ was Phase II tablet administered with low-fat meal; Treatment I was Phase III 
Table II Geometric Mean (Geometric CV\%) Pharmacokinetic Parameters for GDC-08 I O Following a Single Oral Dose of 200 mg GDC-08 I 0 (Treatments A to D): Part I

\begin{tabular}{|c|c|c|c|c|}
\hline \multirow[b]{2}{*}{ PK Parameter } & \multicolumn{4}{|l|}{ Treatment $^{\mathrm{a}}$} \\
\hline & $\begin{array}{l}\text { A } \\
200 \text { mg GDC-08 I0 } \\
\text { Phase II } \\
\text { Tablet } \\
\text { NMG salt; } 10 \% \text { SLS, } \\
\text { I } 5 \% \mathrm{NaHCO}_{3} \\
(n=17)\end{array}$ & $\begin{array}{l}\text { B } \\
200 \text { mg GDC-08I0 } \\
\text { Phase III } \\
\text { Prototype I Tablet } \\
\mathrm{NMG} \text { salt; } 2 \% \mathrm{SLS} \\
\text { I } 5 \% \mathrm{NaHCO}_{3} \\
(\mathrm{n}=15)\end{array}$ & $\begin{array}{l}\text { C } \\
200 \text { mg GDC-08 I0 } \\
\text { Phase III } \\
\text { Prototype } 2 \text { Tablet } \\
\text { NMG salt; } 2 \% \text { SLS, } \\
10 \% \mathrm{NaHCO}_{3} \\
(\mathrm{n}=17)\end{array}$ & $\begin{array}{l}\text { D } \\
200 \text { mg GDC-08I0 } \\
\text { Phase III } \\
\text { Prototype } 3 \text { Tablet } \\
\text { NMG salt; } 2 \% \text { SLS, } \\
5 \% \mathrm{NaHCO}_{3} \\
(\mathrm{n}=15)\end{array}$ \\
\hline $\begin{array}{l}t_{\max }^{b}(h) \\
C_{\max }(n g / m l) \\
A \cup C_{0-t}(h r * n g / m l) \\
t_{1 / 2}(h) \\
G M R(90 \% \mathrm{Cl}) \text { of } C_{\max }(\%) \\
G M R(90 \% \mathrm{Cl}) \text { of } A \cup C_{0-t}(\%)\end{array}$ & $\begin{array}{l}2.00(1.00-4.00) \\
3140(37.2) \\
8020(28.7) \\
18.14(73.7) \\
{[n=13]} \\
\text { NA } \\
\text { NA }\end{array}$ & $\begin{array}{l}3.00(1.00-4.02) \\
2540(47.4) \\
7420(29.0) \\
17.41(48.0) \\
{[n=12]} \\
82 \%(66-102 \%) \\
90 \%(82-100 \%)\end{array}$ & $\begin{array}{l}3.00(1.00-4.00) \\
2440(42.8) \\
7310(26.2) \\
14.33(36.1) \\
{[n=12]} \\
78 \%(63-96 \%) \\
91 \%(83-100 \%)\end{array}$ & $\begin{array}{l}2.00(0.50-4.00) \\
2010(49.5) \\
6460(30.5) \\
13.40(77.5) \\
{[n=11]} \\
66 \%(53-82 \%) \\
83 \%(75-91 \%)\end{array}$ \\
\hline
\end{tabular}

NA, not applicable

${ }^{a}$ All treatments were administered 30 min after the start of a low-fat meal

b Median (range)

Prototype 1 tablet administered under fasted conditions; and Treatment J was Phase III Prototype 1 tablet administered with low-fat meal.

Plasma concentration-time profiles and PK parameters of GDC-0810 following administration of a single oral dose of $600 \mathrm{mg}$ GDC-0810 as Treatments $\mathrm{H}$ to J are shown in Fig. 3c and Table IV, respectively. GMRs of GDC-0810 as Treatments I and J relative to the reference formulation (Treatment $\mathrm{H}$ ) are summarized in Table IV.
Treatment $\mathrm{J}$ showed significantly higher levels of total exposure when administered in the fed state compared to administration in the fasted state (Treatment $\mathrm{I}$ ), when measured by $\mathrm{C}_{\max }$ or $\mathrm{AUC}_{0-\mathrm{t}}$ (approximately $36 \%$ higher; $p=0.026$ and $26 \%$ higher; $p=0.024$, respectively).

There was no statistically significant difference in total exposure, when measured by $\mathrm{AUC}_{0-\mathrm{t}}$ or in peak exposure measured by $\mathrm{C}_{\max }$ for Treatment $\mathrm{J}$ compared to Treatment $\mathrm{H}$ when both were administered in the fed state $(p=0.53$ and $p=0.33$, respectively).

Table III Geometric Mean (Geometric CV\%) Pharmacokinetic Parameters for GDC-08 I 0 Following a Single Oral Dose of 200 mg GDC-08 I 0 (Treatments E to $G)$ : Part 2

\begin{tabular}{|c|c|c|c|}
\hline \multirow[b]{2}{*}{ PK Parameter } & \multicolumn{3}{|l|}{ Treatment $\mathrm{t}^{\mathrm{a}}$} \\
\hline & $\begin{array}{l}\text { E } \\
200 \text { mg GDC-08 I0 } \\
\text { Phase II } \\
\text { Tablet } \\
\text { NMG salt; I0\% SLS, } \\
\text { I } 5 \% \mathrm{NaHCO}_{3}(n=15)\end{array}$ & $\begin{array}{l}\text { F } \\
200 \text { mg GDC-08 } 10 \\
\text { Phase III } \\
\text { Prototype } 4 \text { Tablet } \\
\text { Free Acid; } 2 \% \text { SLS, } \\
\text { I5\% NaHCO } \\
(n=15)\end{array}$ & $\begin{array}{l}\text { G } \\
200 \text { mg GDC-08 } 10 \\
\text { Phase III } \\
\text { Prototype } 5 \text { Tablet } \\
\text { Spray-Dried Amorphous Dispersion; } \\
2 \% \mathrm{SLS}, 15 \% \mathrm{NaHCO}_{3} \\
(\mathrm{n}=15)\end{array}$ \\
\hline $\begin{array}{l}t_{\max }{ }^{b}(h) \\
C_{\max }(n g / m l) \\
A \cup C_{0-t}\left(h r^{*} n g / m l\right) \\
t_{1 / 2}(h) \\
G M R(90 \% \mathrm{Cl}) \text { of } C_{\max }(\%) \\
G M R(90 \% \mathrm{Cl}) \text { of } A \cup C_{0-t}(\%)\end{array}$ & $\begin{array}{l}2.00(1.00-4.00) \\
2510(80.4) \\
7180(50.2) \\
14.56(38.5) \\
{[n=9]} \\
\text { NA } \\
\text { NA }\end{array}$ & $\begin{array}{l}3.10(2.00-4.07) \\
2070(85.8) \\
6180(53.0) \\
18.57(46.2) \\
{[n=9]} \\
82 \%(67-102 \%) \\
86 \%(79-94 \%)\end{array}$ & $\begin{array}{l}3.05(1.00-4.02) \\
2830(75.5) \\
7330(51.9) \\
18.53(34.3) \\
{[n=12]} \\
113 \%(91-139 \%) \\
102 \%(94-111 \%)\end{array}$ \\
\hline
\end{tabular}

NA, not applicable

${ }^{a}$ All treatments were administered 30 min after the start of a low-fat meal

b Median (range) 
Table IV Geometric Mean (Geometric CV\%) Pharmacokinetic Parameters for GDC-08 I 0 Following a Single Oral Dose of 600 mg GDC-08 0 (Treatments $\mathrm{H}$ to J): Part 3

\begin{tabular}{|c|c|c|c|}
\hline \multirow[b]{2}{*}{ PK Parameter } & \multicolumn{3}{|l|}{ Treatment } \\
\hline & $\begin{array}{l}\mathrm{H} \\
600 \text { mg GDC-08I0 } \\
\text { Phase II } \\
\text { Tablet } \\
\text { NMG salt; } 10 \% \mathrm{SLS}, \\
\text { I5\% NaHCO } \\
\mathrm{Fed}^{\mathrm{a}} \\
(n=13)\end{array}$ & $\begin{array}{l}\text { I } \\
600 \text { mg GDC-08I0 } \\
\text { Phase III } \\
\text { Prototype I Tablet } \\
\text { NMG salt; } 2 \% \text { SLS, } \\
\text { I5\% NaHCO } \\
\text { Fasted } \\
(n=13)\end{array}$ & $\begin{array}{l}\text { J } \\
600 \text { mg GDC-08 } 10 \\
\text { Phase III } \\
\text { Prototype I Tablet } \\
\text { NMG salt; } 2 \% \mathrm{SLS}, \\
\text { I5\% NaHCO} \\
\text { Fed } \\
(n=13)\end{array}$ \\
\hline $\begin{array}{l}\mathrm{t}_{\max }{ }^{\mathrm{b}}(\mathrm{h}) \\
\mathrm{C}_{\max }(\mathrm{ng} / \mathrm{ml}) \\
\mathrm{AUC}_{0-\mathrm{t}}(\mathrm{hr} * \mathrm{ng} / \mathrm{ml}) \\
\mathrm{t}_{1 / 2}(\mathrm{~h}) \\
\mathrm{GMR}(90 \% \mathrm{Cl}) \text { of } \mathrm{C}_{\max } \text { (Fed vs Fast) }(\%) \\
\mathrm{GMR}(90 \% \mathrm{Cl}) \text { of } \mathrm{AUC} \mathrm{C}_{0-\mathrm{t}} \text { (Fed vs Fast) }(\%) \\
\mathrm{GMR}(90 \% \mathrm{Cl}) \text { of } \mathrm{C}_{\max } \text { (Test vs Ref) }(\%) \\
\mathrm{GMR}(90 \% \mathrm{Cl}) \text { of } \mathrm{AUC} \mathrm{C}_{0-\mathrm{t}} \text { (Test vs Ref) (\%) }\end{array}$ & $\begin{array}{l}3.00(2.00-4.00) \\
13,000(57.0) \\
48,100(41.1) \\
14.82(37.5)[n=10] \\
\text { NA } \\
\text { NA } \\
\text { NA } \\
\text { NA }\end{array}$ & $\begin{array}{l}1.00(0.93-4.00) \\
8320(46.4) \\
35,900(49.8) \\
14.15(50.7)[\mathrm{n}=9] \\
\text { NA } \\
\text { NA } \\
\text { NA } \\
\text { NA }\end{array}$ & $\begin{array}{l}3.00(2.00-4.02) \\
11,200(54.4) \\
44,700(38.5) \\
15.87(46.4)[\mathrm{n}=10] \\
137 \%(109-171 \%) \\
126 \%(107-148 \%) \\
88 \%(70-110 \%) \\
94 \%(80-111 \%)\end{array}$ \\
\hline
\end{tabular}

NA, not applicable

${ }^{a}$ Fed: treatment administered 30 min after the start of a low-fat meal; fasted: treatment administered after a minimum 8-h fast

Fed vs. fasted: Treatment J vs. Treatment I, Test vs. Ref; Treatment J vs. Treatment H

b Median (range)

\section{DISCUSSION}

GDC-0810 was provided for use in Phase I/II clinical studies in a tablet formulation using NMG salt with $10 \%$ SLS and $15 \% \mathrm{NaHCO}_{3}$. However, high drug loading and atypical levels of SLS presented challenges for drug product manufacturability. The formulation showed poor powder flow properties, which resulted in high variability of tablet weight and tablet hardness. In addition, sufficient tablet hardness suitable for downstream coating and handling could not be achieved with this formulation. Hence, further formulation optimization was required to provide a tablet product for use in future clinical studies or for commercial use.

The strategy for Phase III formulation development was focused on the optimization of the levels of excipients in Phase II tablet formulation to improve manufacturability without decreasing drug exposure and stability. A series of design of experiments (DOE) were conducted with the aim of evaluating the impact of formulation components on tablet disintegration, in vitro dissolution, and drug product manufacturability. A significant reduction in the tablet hardness and prolonged tablet disintegration time were observed with increasing the level of SLS in the formulation (data not shown). The results also revealed that the level of sodium bicarbonate impacted in vitro dissolution of GDG-0810 the most. The dissolution rate increased with increasing levels of sodium bicarbonate in the formulation (7). To confirm the effect of these excipients on in vivo drug exposure and identify the optimal levels of excipients in Phase III formulation, a relative bioavailability study was planned.

Traditional approaches to assess dissolution characteristics of the formulation include in vitro dissolution methods followed by preclinical studies. The poor correlation between human and animal bioavailability posed a risk for the optimized formulation that necessitated its clinical testing $(15,16)$. Nonetheless, conventional clinical assessment was timeconsuming and costly because it was based on multiple cycles of in vitro and preclinical testing for formulation selection, scaling up, and generating stability data prior to clinical dosing. To evaluate PK performance of the formulation efficiently, RapidFACT ${ }^{\circledR}$ was employed to accelerate the screening of the new formulations in human subjects, by avoiding the need to pre-determine and pre-manufacture clinical formulation compositions based on such surrogate measures. In addition, a two-dimensional formulation design space was used within the RapidFACT ${ }^{\circledR}$ program to maximize the freedom to adjust SLS and $\mathrm{NaHCO}_{3}$ levels in the formulation in response to emerging PK data.

This "Make and Test in Parallel" strategy therefore allowed the rapid and iterative adjustment of formulation compositions in real-time to maximize the potential to achieve the TPP within a single clinical study. RapidFACT ${ }^{\circledR}$ has been previously demonstrated to successfully optimize dissolution characteristics of the formulation. One example of successful implementation of RapidFACT ${ }^{\circledR}$ is the prostate cancer drug abiraterone 
acetate (Zytiga), which had very low bioavailability and a significant positive food effect in men due to inadequate and variable dissolution. The manufacturer then developed a novel formulation with improved solubility and dissolution characteristics. Using RapidFACT ${ }^{\circledR}$, three consecutive reduced doses were tested in the presence of food. A 75\% dose reduction with significant reduction of inter-individual variability was achieved with the novel formulation in a single clinical PK trial (17). RapidFACT ${ }^{\circledR}$ also allowed the potential for post study analysis of in vitro and in vivo datasets to increase product and process understanding in early development. Although not an objective of the current study previous publications have demonstrated for example how RapidFACT ${ }^{\circledR}$ has been used to establish an in vitro-in-vivo correlation (18).

In the current study, the level of SLS in the range of $0-$ $4 \%$ and the level of $\mathrm{NaHCO}_{3}$ in the range of $5-15 \%$ were defined as the two-dimensional formulation design space. The results of formulation development DOE showed that Phase III Prototype 1 tablet formulation containing $2 \%$ SLS and $15 \% \mathrm{NaHCO}_{3}$ demonstrated the best performance in terms of manufacturability and in vitro drug release, followed by Phase III Prototype 2 tablet formulation containing $2 \% \mathrm{SLS}$ and $10 \% \mathrm{NaHCO}_{3}$. Therefore, these two formulations were first selected to be evaluated in Part 1 as compared to the reference Phase I/II tablet formulation. The human PK data of dosing periods 1-3 showed that the plasma GDC-0810 exposure with Phase III Prototype 1 formulation (Treatment B) offered maximum exposure. The reduction in SLS content from 10 to $2 \%$ resulted in a slightly lower $\mathrm{C}_{\max }$ (statistically nonsignificant) while maintaining the extent of exposure $\left(\mathrm{AUC}_{0-\mathrm{t}}\right)$ of GDC-0810 (GMR 90\%), suggesting that 2\% SLS in the formulation would be sufficient to deliver the comparable exposure of GDC-0810 as 10\% SLS. Phase III Prototype 2 formulation (Treatment $\mathrm{C}$ ) showed slightly lower $\mathrm{C}_{\max }$ but comparable $\mathrm{AUC}_{0-\mathrm{t}}$ as the Prototype 1 formulation, suggesting that the level of $\mathrm{NaHCO}_{3}$ varying from 15 to $10 \%$ did not significantly affect the in vivo GDC-0810 exposure. Therefore, an interim decision was made, based on the available safety, tolerability, and PK data following completion of Period 3, to select the Phase III Prototype 3 formulation containing 5\% $\mathrm{NaHCO}_{3}$ to be manufactured and dosed in Period 4 in Part 1. It appears that $\mathrm{C}_{\max }$ and $\mathrm{AUC}_{0 \text {-t }}$ of the Prototype 3 formulation was significantly lowered. These results suggest that at least $15 \% \mathrm{NaHCO}_{3}$ is needed to maintain the plasma exposure of GDC-0810 comparable to that of the Phase I/II formulation. Based on these findings from Part 1 using the 'Make and Test in Parallel' approach, the composition of excipients was set to $2 \%$ SLS and $15 \%$ $\mathrm{NaHCO}_{3}$ for further testing in Part 2.
In Part 2 of the study, GDC-0810 PK with the free acid formulation (Treatment F) and the spray-dried amorphous solid dispersion formulation (Treatment G) were assessed and compared with Phase II NMG salt formulation (Treatment E). The test formulations, $\mathrm{F}$ and $\mathrm{G}$, included SLS content of $2 \%$ and $\mathrm{NaHCO}_{3}$ content of $15 \%$ and were administered following a low-fat meal. There was no statistically significant difference between the formulations tested, suggesting that the form of active pharmaceutical ingredient in these formulations of GDC-0810 did not influence the bioavailability of the drug. Moreover, the initial plan to develop the free acid form for Phase III formulation was impacted by the emergence of a new polymorph with 3-folds reduction in solubility. Therefore, based on these findings as well as the results of Part 1 and Part 2, Phase III Prototype 1 formulation containing NMG salt with $2 \%$ SLS and $15 \% \mathrm{NaHCO}_{3}$ was selected for further testing in Part 3.

In Part 3 of the study, the Phase III Prototype 1 formulation, containing NMG salt, $2 \%$ SLS and 15\% $\mathrm{NaHCO}_{3}$, was administered following a low-fat meal but at a higher dose of $600 \mathrm{mg}$ GDC-0810. The plasma exposure of GDC-0810 with Phase III prototype 1 formulation was comparable with the Phase I/II formulation even at the clinically relevant dose of $600 \mathrm{mg}$, confirming the findings at $200 \mathrm{mg}$ in Part 1. These results are in line with the expected PK linearity of GDC-0810 with respect to dose.

In addition, when the PK of Phase III prototype formulation 1 at $600 \mathrm{mg}$ dose in fed state (low-fat) was compared with fasted state in Part 3, approximately 30\% increase in bioavailability with food was observed. The increase in exposure in the presence of food was statistically significant and could be a result of food aiding the solubility of GDC-0810. Furthermore, the $t_{\max }$ in the fed state was increased and is expected to be a result of a slower rate of gastric emptying observed in the fed state.

Variability in exposure parameters of GDC-0810 was extensive in this study, with geometric $\mathrm{CV} \%$ ranging between 26.2 and $85.8 \%$. This is not unusual for compounds requiring excipients to increase solubility. The elimination half-life was unchanged for all formulations administered at all dose levels tested, with values of between $13.4 \mathrm{~h}$ and $18.6 \mathrm{~h}$.

\section{CONCLUSIONS}

Overall, the study successfully identified a Phase III formulation with a reduced SLS content which, when administered after a low-fat meal, gave comparable exposure to the Phase II formulation. Thus, our novel 'Make and Test in Parallel' approach allowed the optimization of a GDC-0810 formulation in the most time- and cost-efficient fashion based on clinical data. In addition, given the higher exposure with food, the administration of GDC-0810 was recommended with food. 


\section{ACKNOWLEDGMENTS AND DISCLOSURES}

We would like to thank Mindy Sivasubramanian, Lindsay Crist, Marie Borin, Po-Chang Chiang, and Scott Lam from Genentech, and Sue Melbourne, Nand Singh and John McDermott from Quotient Sciences for their contributions to this study. The authors are either employees of Genentech Inc. and/or stockholders of the Roche Group; Helen Walker is an employee of Quotient Sciences. Editorial assistance was provided by AnshinBiosolutions Corp.

Open Access This article is distributed under the terms of the Creative Commons Attribution 4.0 International License (http://creativecommons.org/licenses/by/4.0/), which permits unrestricted use, distribution, and reproduction in any medium, provided you give appropriate credit to the original author(s) and the source, provide a link to the Creative Commons license, and indicate if changes were made.

\section{REFERENCES}

1. FerlayJ, Soerjomataram I, Ervik M, et al. GLOBOCAN 2012 v1.0, Cancer incidence and mortality worldwide: IARC CancerBase No. 11 [Internet]. 2013; Available from: http://globocan.iarc.fr. Accessed Sep 25, 2017.

2. Lumachi F, Brunello A, Maruzzo M, Basso U, Basso SM. Treatment of estrogen receptor-positive breast cancer. Curr Med Chem. 2013;20(5):596-604.

3. Lumachi F, Santeufemia DA, Basso SM. Current medical treatment of estrogen receptor-positive breast cancer. World J Biol Chem. 2015;6(3):231-9.

4. Lai A, Kahraman M, Govek S, Nagasawa J, Bonnefous C, Julien J, et al. Identification of GDC-0810 (ARN-810), an orally bioavailable selective estrogen receptor degrader (SERD) that demonstrates robust activity in Tamoxifen-resistant breast Cancer Xenografts. J Med Chem. 2015;58(12):4888-904.

5. Bi M, Kyad A, Kiang YH, Alvarez-Nunez F, Alvarez F. Enhancing and sustaining AMG 009 dissolution from a matrix tablet via microenvironmental $\mathrm{pH}$ modulation and supersaturation. AAPS PharmSciTech. 201 1;12(4):1157-62.

6. Rao VM, Engh K, Qiu Y. Design of pH-independent controlled release matrix tablets for acidic drugs. Int J Pharm. 2003;252(1-2):81-6.

7. Hou HH, Jia W, Liu L, Cheeti S, Li J, Nauka E, et al. Effect of microenvironmental $\mathrm{pH}$ modulation on the dissolution rate and Oral absorption of the salt of a weak acid - case study of GDC0810. Pharm Res. 2018;35(2):37.

8. EMA. Background review for sodium laurilsulfate used as an excipient. In. London: EMA/CHMP/351898/2014 2015.

9. Grass GM, Sinko PJ. Physiologically-based pharmacokinetic simulation modelling. Adv Drug Deliv Rev. 2002;54(3):433-51.

10. McDermott J, Scholes P. Formulation design space: a proven approach to maximize flexibility and outcomes within early clinical development. Ther Deliv. 2015;6(11):1269-78.

11. Scholes P, McDermott J. Application of formulation design space to drive rapid development and clinical optimization of drug products - five years of innovation. AAPS; 2014; San Diego. California. .

12. McDermott J, Connor A, Sidhu S, Mayes B, Moussa A, Ganga S. Rapid formulation development and clinical evaluation of enabled formulations of IDX-719. AAPS; 2014; San Diego. California.

13. Crowley K, McDermott J, Scholes P. Integrated formulation and clinical programs to realize the maximum potential of amorphous dispersion-based products. Baltimore: AAPS Arden House; 2016.

14. McDermott J, Patrick L, Connor A, Collier J, Lai M. A phase I program to assess the pharmacokinetics of a new salt form of CO1686 and prototype formulations in healthy volunteers. AAPS; 2015; Orlando, Florida.

15. Grass GM, Sinko PJ. Effect of diverse datasets on the predictive capability of ADME models in drug discovery. Drug Discov Today 2001;6(12):(Suppl.) S54 -S61.

16. Musther H, Olivares-Morales A, Hatley OJ, Liu B, Rostami Hodjegan A. Animal versus human oral drug bioavailability: do they correlate? Eur J Pharm Sci. 2014;57:280-91.

17. Solymosi T, Otvos Z, Angi R, et al. Novel formulation of abiraterone acetate might allow significant dose reduction and eliminates substantial positive food effect. Cancer Chemother Pharmacol. 2017;80:723-8.

18. Kane Z, Shao J, Christopher R, Shanahan W, Stevens L, Wilby A, McDermott J, Mair S. Utilization of RapidFACT ${ }^{\circledR}$ strategies to evaluate and develop an in vitro -in vivo correlation (IVIVC) for modified release formulations of Lorcaserin HCl. CRS; 2015; Edinburgh, Scotland. 